\title{
Perceptions of Psychosocial Healing and the Truth and Reconciliation Commission in South Africa
}

\author{
Cheryl de la Rey and Ingrid Owens \\ Department of Psychology \\ University of Cape Town
}

\begin{abstract}
Like many other societies that have dealt with the question of how to achieve closure of a past of oppression while simultaneously working toward national reconstruction and reconciliation, South Africa turned to the concept of a truth commission. Public testimony constitutes the central mechanism in the South African Truth and Reconciliation Commission (TRC) process. Through the use of social constructionism as a broad framework in which the testimony method may be located, this descriptive study examines various narratives to uncover understandings of healing and the modes of healing invoked by both victims and those facilitating the healing process. Two data sources were used: testimony transcripts from public hearings of the TRC and transcripts from interviews with key players in the process. Thematic analysis revealed that there are multiple understandings of healing but overall, the narratives affirmed the therapentic value of the testimony method. The central issue under discussion in the article is the connectedness between individual healing and national reconciliation.
\end{abstract}

The South African Government of National Unity (GNU), elected into office in April 1994 after a 4-year period of negotiations, faced the tricky question of how to confront the wrongs of the past while simultaneously building a shared nationhood. Wilson (1995) argued that truth commissions have become one of the main mechanisms by which transitional governments seek to create legitimacy for state institutions still tainted by the legacy of the past. Indeed, it was to the concept of a truth commission that South Africa turned in pursuit of national reconciliation, unity, and peace. This article briefly describes the South African Truth and 
Reconciliation Commission (TRC), and then examines perceptions of psychosocial healing within the reconciliation process.

\section{THE SOUTH AFRICAN TRUTH AND RECONCILIATION COMMISSION}

The agreement to replace the apartheid state with a GNU had significant consequences for the reconstruction and rehabilitation of South African society. As pointed out by Wilson (1995), despite the high visibility of the elections and apparently radical legal reforms, there was a continuity of state organisation and function. Through a GNU the civil service institutions and personnel of the apartheid state were ensured continuity of tenure. Agencies of state security such as the defence force and the police remained within the hands of personnel who were allegedly involved in apartheid-related human rights violations. The South African negotiated settlement required substantial compromise and did not mark a "clean break" with the past (Du Plessis, 1994, in Boraine, Levy \& Schefer, 1994).

Because of lack of agreement on issues such as indemnification and amnesty for exiles and members of the apartheid state, the question of a truth commission was only discussed during the final stages of the negotiations. In the end, the negotiating parties agreed to the postponement of any legislation on the issue until after the elections. This meant that South Africa entered the period of transitional governance without a general amnesty law, the first country in Africa to do so, according to the Minister of Justice (Boraine et al., 1994).

The Promotion of National Unity and Reconciliation Bill was signed by President Mandela on May 19, 1995 and it became an Act of Parliament in July, just over 1 year after the democratic elections. This is the legislation that allowed for the existence of the TRC.

Key words that were often repeated in the motivations for a TRC were truth, healing, and reconciliation. It was argued that through the process of meeting these objectives, the TRC would restore the moral order of South African society, create a culture of human rights and respect for the rule of law, and prevent the past happening again.

The President, in consultation with the Cabinet, appointed 17 commissioners with Archbishop Tutu as the Chairperson. The commissioners preside over three committees: the Committee on Human Rights Violations, the Committee on Amnesty, and the Committee on Reparation and Rehabilitation of Victims. Each of these three committees has different tasks that are executed with the assistance of specific support structures such as an investigations arm, a research unit, and a media department.

The Committee on Human Rights Violations is responsible for conducting public hearings throughout the country. The objective of these public hearings was seen as providing victims of human rights abuses the opportunity to tell their stories 
and thereby come to terms with the pain and trauma of the past. Whether the TRC as set up was able to meet this objective became a moot question fiercely debated by psychologists.

\section{PERSPECTIVES FROM PSYCHOLOGY}

Prior to the working of the TRC, there were some psychologists who expressed their support, others who were skeptical of the proposed process and those who saw it as more harmful than beneficial. However, once the work of the TRC was underway, there was considerable debate among psychologists about whether the objective of healing was being achieved through the chosen process. In the past year the discussions on the psychosocial aspects of the present truth and reconciliation process have intensified. Unfortunately, there has been more talk than publication, in particular publication of contextually relevant research.

Nonetheless, a body of knowledge that has direct bearing on the mechanism most central to the process utilised by the TRC is that on testimony as a therapeutic technique. As van der Veer (1992) explained: "The point of departure of this method is to encourage the traumatized person to describe his traumatic experiences in as much detail as possible, as though he was giving evidence as witness for the prosecution" (p. 150).

The aforementioned delineation of the method depicts the mechanism that embodies the South African truth and reconciliation process, namely, testimonygiving. Since the beginning of the work of the TRC, in venues across the country, victims of human rights abuses have given testimony, telling their stories of suffering. In a similar vein to the use of the testimony method in therapy, the details of the story as told by the victim become a concrete written text. However, there are some crucial differences between the therapeutic context and that of the South African TRC. A key distinguishing feature is the explicitly public nature of giving testimony in the South African process where the individual tells his or her story to a panel of commissioners in the presence of an audience that includes journalists; very often, there is also live television coverage.

Despite this difference, the approach to the testimony method as used by Cienfeugos and Monelli (1983) with victims of the military dictatorship in Chile resonates with the South African situation. Indeed, in the deliberations on a suitable mechanism for dealing with past human rights abuses, South African decision makers were strongly influenced by the Chilean experience (Boraine \& Levy, 1995). Therefore, the approach of Cienfeugos and Monelli warrants further explication.

\section{Testimony As a Method}

Two components of the method are seen as crucial in its effectiveness in bringing about healing: first, the verbal articulation of the facts, events, and details of the 
traumatic experience and second, the expression of the emotional aspects of the trauma. In the telling of the details, the politics of the experience is also a topic of conversation. Moreover, Cienfeugos \& Monelli (1983) noted that the form and symbolism of the process are significant to its successful outcome. The resemblance to giving evidence for prosecution is seen as especially important because it can create the possibility for the constructive channelling of strong negative emotions such as anger and aggression. So, too, is representation of the testimony in writing, in the form of a statement, because it gives recognition to the significance of the victim's suffering.

Testimony as a therapeutic technique does not fall within a singular theoretical framework; instead it can be explained within more than one theoretical perspective (van der Veer, 1992). When used as a therapeutic technique in interventions aimed primarily at the individual, testimony is often used within a psychodynamic framework. In such instances the focal points are trust, resistance, transference and countertransference, and testimony as catharsis and restoration.

However, the South African public hearings address experiences of trauma not merely at the individual level but also at the level of the collective-social. In this context testimony-giving in the form of the public hearing is not simply about the reconstruction of private-individual trauma but also a social-political process through which the past abuses are reconstructed and documented as public historical knowledge. Thus it is a constitutive narrative in which boundaries between individual and social are not clearly distinguishable. Here the theoretical work on collective memory is germane, in particular the approach of Middleton and Edwards (1990) who noted that, "In the contest between varying accounts of shared experiences, people reinterpret and discover features of the past that become the context and content for what they will jointly recall and commemorate on future occasions" (p. 7).

In reconstructing traumatic events that occurred in past years, individuals giving public testimony rely on memory. In the process there is contestation between different accounts of events, and the task before the TRC is that of establishing an accurate record of past human rights abuses. This is a socially significant process through which past reality is collectively reconstructed and documented. This will be the basis of what future generations will remember. The South African process, therefore, is an embodiment of the social foundation and context of individual memory as postulated by Middleton and Edwards (1990). Their work is however, located within a broader theoretical framework, namely social constructionism.

\section{Social Constructionism, Memory, and Testimony}

The vast and growing literature on social constructionism is not reviewed here, instead only those aspects most directly relevant to this article are highlighted. 
One of the most important contributions of social constructionism to psychological theorizing is that it has forced a rethinking of the legacy of a dualistic conceptualisation of the individual and the social. Instead, from a social constructionist perspective lives are seen as simultaneously individual and social. Another key feature of social constructionism is the emphasis on the social embeddedness of all conceptualisations of what is accepted as knowledge and as truth (McNamee \& Gergen, 1992). Textual formulations such as storytelling and testimonies are viewed as central to our constructions of ourselves and the world. Language and its limitations are consequently part of the main currency of this theoretical framework. Our textual accounts are viewed as constituting ourselves, our histories, and our futures (McNamee \& Gergen, 1992).

In applying social constructionism to the truth and reconciliation process, we come to see memories and testimonies as arising from social relatedness and exchange, and mediated through language. Through the ongoing exchange that happens in the context of the way the process is structured, the history of the workings of apartheid will be reconstructed, historical activity in individual lives will be illuminated, common understandings will evolve, and the future will be constituted.

\section{FOCUS OF THIS RESEARCH}

Using social constructionism as a broad framework, in our research we examine how various participants in the truth and reconciliation process think and talk about healing. As psychologists we have chosen to focus on the topic of healing that, in the context of the TRC, is a broad one that has been much debated but much less researched. Our descriptive study examines various narratives to uncover (a) how different people understand healing and (b) the modes of healing invoked by both victims and those facilitating the healing process.

\section{METHODOLOGY}

A qualitative framework was selected because of its congruence with social constructionism as the framework for this study and because it was viewed as most appropriate to an investigation of perceptions of healing in the truth and reconciliation process. Two data sources were used: testimony transcripts from public hearings of the TRC and transcripts from interviews conducted by one of the authors. The nature of the data differ in that the testimonies are not the result of specific questions on healing processes as are the interviews. This form of data triangulation was used to provide a "multi-dimensional approach" (Sidell, 1993, p. 108). 
From the interviewees and testifiers three subject positions emerge:

1. Victims of human rights abuse: Five testimony transcripts from the first round of public hearings in the Western Cape were selected. The transcripts included: (a) Testimony 1, a male victim of a shooting, with evidence also given by his wife and mother; (b) Testimony 2, evidence given by the sister and neighbour of a male victim who died from shooting; (c) Testimony 3 , a male who was the victim of torture, with evidence also given by his father; (d) Testimony 4, a woman victim who survived a shooting; and (e) Testimony 5, a woman victim who survived a massacre and the death of her husband.

2. Commissioners from the TRC: Unstructured one-to-one interviews were held with two members of the Rehabilitation and Reparations Committee and one member of the Human Rights Committee. Although the Amnesty Committee is not directly involved in the healing process of victims, we wished to interview someone from this committee because of the controversy concerning the amnesty of perpetrators of human rights abuses and its effects on the healing process for victims. Several attempts to secure an interview with a commissioner from the Amnesty Committee resulted in a brief telephone conversation with one Committee member.

3. Nongovernmental Organisations (NGOs): To gain a perspective outside of the TRC, three people from three different nongovernmental organisations who work with victims of human rights abuses were interviewed. A clinical psychologist employed by a trauma centre that has played a central role in assisting victims of violence and torture was selected. The second interviewee was the coordinator of a community organisation that assists people in gaining access to the TRC and also provides counselling for victims. The third interviewee was a religious minister who was also an anti-apartheid activist and a victim of human rights abuse. $\mathrm{He}$ represented a grouping of religious organisations that has been playing a substantial role in facilitating healing through workshops.

Given the descriptive, exploratory nature of this study, unstructured interviews were chosen as a method of data collection. Potential interviewees involved in the TRC process were identified on the basis of convenience and accessibility to the researchers. Interviewees were informed that the researchers were interested in their perceptions of healing in relation to the truth and reconciliation process. Thus the interviews were framed by the broad question: "Tell me how you view the process of the Commission in relation to healing." All interviews were audiotaped after permission was granted to do so.

Due to the bulk of the data gathered, thematic analysis was conducted using a coding framework that emanated from the content of the data. In the analysis presented later we quote liberally from the testimonies and interview transcripts. This is done to reveal the multiple meanings in the varied descriptions and metaphors that respondents used to express their views. The Results and Discussion 
are interwoven for continuity and to allow for a more integrated presentation of the multiplicity of understandings of healing and the implications thereof.

\section{RESULTS AND DISCUSSION}

\section{Emergent Themes and Their Meanings}

It is important to note that false boundaries are often used here to delineate different themes. In reality, each theme is integrally linked and influenced by other themes. Certain major themes (e.g., healing) explode into a myriad of subthemes and components. The process of gaining insight into the rich interdependence of themes and subthemes is exciting and creative. Indeed, it seemed nearly impossible to translate into a linear written form. An attempt to provide an overall picture of the themes to be discussed can be seen in Figure 1.

There was much talk of suffering in all the data gathered. In talking about healing, the participants invoked conceptualisations of suffering. As one of the interviewees remarked: "To know about healing we must understand from what they are healing." Hence, the findings presented below begin with an analysis of suffering as it emerged in the narratives.
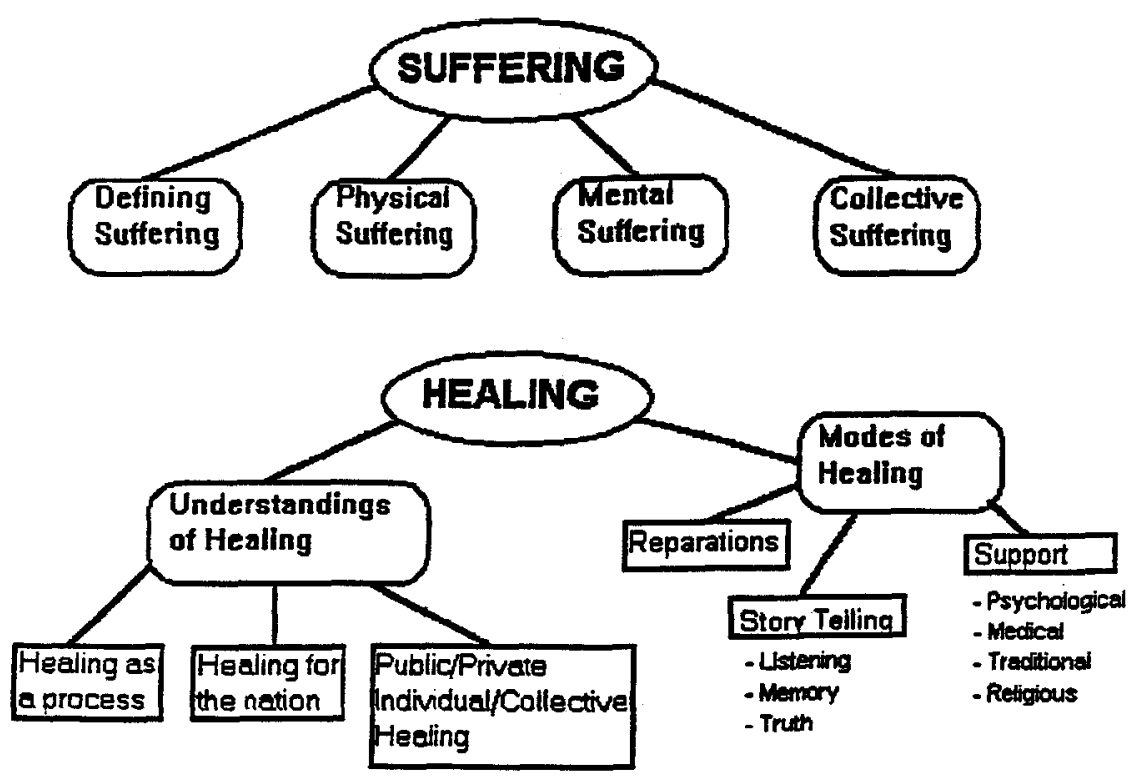

FIGURE 1 Graphical representation of themes and sub-themes. 


\section{Suffering}

Three dimensions of suffering surfaced in the data: physical, mental, and collective. Across the five testimonies there was approximately $50 \%$ more reference made to physical suffering as opposed to mental suffering.

The descriptions of physical suffering varied as to the nature of the bodily trauma experienced. Survivors referred to head wounds, leg wounds, stomach injury, vaginal injury, and facial injury. They gave two forms of evidence concerning physical suffering. First, they spoke of the moments when the abuse occurred. An example is a victims's description of how he was beaten up: "They tripped me and I fell, they were kicking me, I tried to cover my face because I didn't want my face at least to be injured but they were too many for me, they overpowered me."

Clear descriptions of moments of death were recalled when a witness told of a victim who "was shot in the head ... the other one was just about to die, he was still foaming. He was still gasping." Witnesses gave clear accounts of the fate of various internal body parts. They told of how they saw a man "digging up the hole for the brains of this other boy" and how a man "stood there with my son's intestines in his hands."

A second form of description was about the physical suffering that persisted after the abuse. For example, a mother told of the physical state of her son: "He has a lot of plastic tubes ... in his stomach ... he can't tolerate food like other people." Another woman talked of her continued physical link with the abuse: "I have several bullets in my body, some are still in my leg ... some are somewhere in my body ... some of the bullets are in my vagina." These concrete descriptions stand in contrast to abstract references to mental suffering.

However, an indication of the depth of emotional suffering experienced by testifiers was evident in the words used to describe emotions linked to the suffering, and in the responses of certain commissioners. People frequently intensified the emotion by using the word "very," as in "very sad," "very disturbed," and "very angry." The words "pain" and "hurt" were repeated throughout the testimonies and stronger terms such as "grief" and "agony" were also used to describe the depth of the suffering. The emotions varied as testifiers and commissioners reported feeling "scared," "sad," "shocked," "anxious," "bewildered," "angry," and filled with "absolute horror."

The tendency to talk more about physical rather mental suffering, as revealed in the narratives, raises some critical questions about testimony as a therapeutic method. The emphasis it places on the value of spoken language may limit affective expression. On the other hand, the greater focus on the physical in these narratives may be due to the nature of the testimony-giving process, where people are asked to tell their story in a way that suggests that a factual narrative rather than an emotional one should be given. Recognition of both the physical and the emotional suffering of victims of human rights abuse in South Africa is clearly a complex task. 
The discussion thus far has focused on the suffering of the individual, yet reference was also made to the suffering of the South African nation as a whole. In one of the interviews with NGO personnel, a more general form of mental suffering experienced by victims of apartheid was described. The participant explained "how mistrust has been engendered into people's psyches over years of subjugation and suppression."

National suffering was in particular referred to by the commissioners during the testimonies. During public hearings they reminded those giving testimony that "you are in the company of many people who have suffered over the last years" and "Every time somebody comes up here to share their pain, we all go through the same pain." The consequence of these references to the nation may be that private pain is transformed through a political reframing (Agger \& Jensen, 1990, in van der Veer, 1992). It may achieve both comfort and support for the survivor as well as remind the nation listening to the testimony that this is not the process of one individual but of an individual who is part of and cannot be separated from his or her society. Although the manner in which people have suffered varies widely according to variables such as race, class, gender, and economic standing, the recognition that there has been collective suffering is, however, at the root of the process of national reconciliation.

\section{Healing}

The central point of reflection in this article is the question of how people understand the notion of healing. In the different understandings of healing expressed in the data the foci are those of healing as a process: as public, private, individual, and collective.

Healing as a process. There were many references to healing as a process, especially from the interviews with NGO personnel. This may be indicative of the close contact that NGO personnel have with victims in a healing capacity. In contrast, some of the TRC staff indicated that they were becoming caught up in the administrative and bureaucratic mechanisms of the Commission.

Besides the frequent appending of the word "process" to the word "healing," the sense of a process emerged through people using metaphors of a journey and referring to movement and time. Mention was made of beginnings but no ends. For example, a commissioner described the hearings as "the beginning of the healing." A psychologist reflecting on her work said that she was "trying to help people recreate processes that can help them move." The image of a journey was invoked by an interviewee who spoke from the experience of facilitating workshops on healing: 
What inspires you is the journey from slavery to freedom ... its about the journey from victim to survivor to victor. ... Uh and it's a process, obviously it can be very, very long. ... This model can help people to take step one, step two on a long long road.

Healing for the nation. Healing as a national process was expressed from all three subject positions in the data. Part of the process of national healing was seen as the sharing of pain with the nation. There was the perception that the pain of individual victims as part of the nation can teach the country in its quest to heal. The Chairperson of the Commission closed one of the testimonies confirming that "we want our nation to know everything that was done in the past ... so that everybody should know that we got it at a very high price." The challenge, though, is how to achieve national healing as well as meet the individual needs of victims.

The process of individual testimonies can be seen as an opportunity for illuminating the interaction between a sociopolitical system of apartheid and the lives of individual South Africans. Analysis of the data highlighted the complexity of the connectedness and tensions that emerge in the attempt to understand the individual in relation to his or her collective society. While the public process of hearings and testimony-giving has the potential to heal many members of South Africa's new nation, the need for privacy amid the very public nature of the TRC surfaced as a theme in the data.

Women were mentioned as a specific group who may require private hearings. The Commission did not begin the process with provision for private hearings. All three commissioners interviewed reported that it was with the realisation that the unintended violation of the right to privacy may explain the absence of women expressing their own suffering in the hearings, and that they became aware of the need for private hearings.

Private hearings and/or closed hearings were not seen as necessarily denoting a healing process that is individual and not collective in effect. Having participated in several workshops on healing, one of the NGO interviewees described how individual and collective healing can occur simultaneously. He believed that group hearings closed to the public (e.g., special group hearings for sexual abuse cases) can be simultaneously collective and individual "because you're healing yourself telling your own story, but you also hear other people's stories."

In working through the data the multiplicity of understandings of healing became evident. As one interviewee said: "I think that for me healing is whatever works for you. Not what I say should work for you."

Modes of healing. Modes of healing that dominated were those of storytelling, reparations, and support systems. 


\section{Storytelling}

Every one of the five testimonies analyzed in this article began with a reference to storytelling that was lauded as a therapeutic process. Several aspects of storytelling were brought to the fore in the transcripts. One was that telling one's story is not simply an individual process; there needs to be a listener and in between the words of the story are silences. Listening was mentioned frequently. In the words of a commissioner: "we are now in a new country where for the first time somebody can listen ... the hearings are about the breaking of silence and how that has begun to heal people." Silence was indeed broken if the detailed stories told by the victims in their testimonies are considered.

In remembering the past, speaking about it, and listening to the stories, interviewees suggested that a process of acknowledgment occurs through which victims are honoured for both the pain that they have suffered and their role in the struggle against apartheid. One of the commissioners explained that she was afraid that she would "find people were crumbling"; instead, she was

amazed to discover that people were up and running, they had renewed freshness because they had come to a public meeting to talk about their experiences. They felt it was painful to talk about it, but the fact that they were given the opportunity gave them a sense of dignity.

The storytelling process is a complex one with many facets. Intimately linked to acknowledgment of the story is a further subtheme, that of the truth. The idea that one path to healing involves the search for a more "truthful" picture of the past was expressed. On a personal level, victims indicated that they want the truth of their stories to be acknowledged. The references to truth were juxtaposed with those of lies. One example was from a man who insisted that the police story was not true. However, neither the police nor the lawyers would acknowledge his story:

I was beaten up but they said to me that I was lying. ... Because I couldn't answer their question well I was told then no I am lying ... the police were denying everything that was happening $\ldots$ and the lawyers representing him were lying so much.

Here the concept of truth is revealed as contestation of accounts of events and the plausibility of who is to be blamed or to be honoured. Indeed, there is confirmation of the point made by Middleton and Edwards (1990) that the truth of the past can be seen as an "epistemological enterprise, created in dialectic and argument between ... contrary positions" (p. 9). The vested interests of different subject positionings are evident in the narratives, such as in the one mentioned earlier. 


\section{Reparations}

According to the approach of Cienfeugos and Monelli (1983), symbolizing the experience of suffering can be important in healing. Reparations may be considered as an instance of symbolism. The TRC legislation defines reparation as including any form of compensation, ex gratia payment, restitution, rehabilitation, or recognition. An important question is whether reparations are seen as a means of helping people to heal.

The healing aspect was made clear in some of the interview transcripts that had statements such as, "there can be no reconciliation and healing before there is reparation." Money was evidently an issue, however. While some felt that the form of the reparation needs to be something visible and concrete, in the press commissioners emphasized that reparation does not specifically refer to financial compensation. One of the commissioners interviewed felt that it was undesirable because she saw financial compensation as "welfarism at its worst, it's handout, it's disempowering, it doesn't work on people's self reliance, dignity ... we would need billions of rand anyway." In this instance the interests of commissioners who are positioned as appointees of the new government are transparent: To affirm the importance of financial reparations would mean difficulties for the TRC because at this stage there were clear messages from the government that money was not available. However, the requests from victims did not merely include money. The testimonies analyzed included requests for help with children, medical assistance, and commemorative symbols.

\section{Support}

The importance of support in bringing about healing was mentioned in the testimonies and interviews. The major sources of support included psychological, medical, religious, and traditional healing systems. Although psychology was not specifically mentioned, there was talk about counselling and the difficulties associated with this. The whole issue of counselling was perceived as problematic. One of the commissioners believed that one of the sources of the problem was that most professionals think about counselling within a pathology model, rather than using a wellness model. She voiced the need to explore other forms of healing that do not see themselves simply as a response to pathology, but focus on healing as a holistic process.

Medical assistance was highly visible in the talk about support. Even more visible was the role of religion as a source of support. Testimonies described how the church assisted in both spiritual and practical ways. Ministers prayed, counselled, and provided instrumental support such as transport. The NGO minister talked of the "Healing of Memories Workshops" that he facilitated. He explained 
that the workshops draw on participants' life experience, religious traditions, biblical passages, and Christian symbols to access emotional issues.

The use of traditional African modes of healing emerged from one perspective only, that of the NGO personnel. One of the NGO workers suspected that traditional forms of healing were being used but that people were not talking about it because such forms of healing were not being sufficiently recognised as credible.

\section{CONCLUSION}

Through the analysis of narratives this study has illuminated the understandings of healing expressed by role players in the TRC process. Overall, the narratives endorsed the finding reported by Cienfeugos and Monelli (1983) that testimony has significant therapeutic value for victims of political repression and torture. Many conditions necessary for the healing of victims of political repression, as specified by the testimony approach of Cienfeugos and Monelli, are present in the TRC process. In telling their stories in the detail required by the Commission, the victim is given the space to integrate the events of the past so that meaningful connections are made with the present and the future. At the same time it allows them to locate their personal histories within the broader political and social context of the country. Furthermore, the documentation of the testimonies will ensure that they form part of the official historical record of human rights abuses during the apartheid regime.

Whether the form of the testimonies as structured by the TRC process permits sufficient space for affective expression is one of the questions that awaits answering through further research. This study is limited by its reliance on narrative. Other methodologies must be used to investigate crucial questions such as the psychological consequences of the TRC process.

Nevertheless, the focus on narrative has shown how each testimony reveals how actions of the state changed the life course of the individual, and how the individual in turn responded in ways that challenged or perpetuated the social conditions of the time. Through these narratives the inextricable boundedness of the personal and the social is elaborated.

The TRC has thus far in its work posed more questions than answers and it has brought to the forefront a number of complexities and dilemmas: some of these are psychological (Can the process bring about healing?), some are philosophical (What is the meaning of truth?), and others are legal (Can justice be achieved?). At the same time it has to deal with an array of differing expectations, needs, and wants. Suffice it to say that a body and process borne of political compromise cannot meet all expectations and fulfil all its objectives equally. The point made by Newham (1995) is notable, namely, that "it is crucial people understand that the Commission is just one mechanism through which to facilitate reconciliation" (p. 7). Through asking questions, offering analyses, and conducting research, psychologists, other 
social scientists, and other sectors of civil society have an important role to play in enhancing the potential of the Commission in realising psycho-social rehabilitation in South Africa.

\section{REFERENCES}

Boraine, A., \& Levy, J. (Eds). (1995). The healing of a nation? Cape Town, South Africa: Justice in Transition.

Boraine, A., Levy, J., \& Schefer, R. (1994). Dealing with the past: Truth and reconciliation in South Africa. Cape Town, South Africa: Institute for Democracy in South Africa.

Cienfeugos, A. J., \& Monelli, C. (1983). The testimony of political repression as a therapeutic instrument. American Journal of Orthopsychiatry, 53, 43-53.

McNamee, S., \& Gergen, K. J. (Eds.). (1992). Therapy as social construction. London: Sage.

Middleton, D., \& Edwards, D. (Eds.). (1990). Collective remembering. London: Sage.

Newham, G. (1995). Truth and reconciliation: Realising the ideals. Indicator $S A, 12(4), 7-12$.

Sidell, M. (1993). Interpreting. In P. Shakespeare, D. Atkinson, \& S. French (Eds.), Reflecting on research practice: Issues in health and social welfare (pp. 107-118). Buckingham, England: Open University Press.

van der Veer, G. (1992). Counselling and therapy with refugees: Psychological problems of victims of war, torture and repression. Chicester, England: Wiley.

Wilson, R. (1995). Manufacturing legitimacy: The Truth and Reconciliation Commission and the Rule of Law. Indicator SA, 13(1), 41-46. 